\title{
Supercritical fluids in biomedical and tissue engineering applications: a review
}

\author{
A. R. C. Duarte ${ }^{* 1,2}$, J. F. Mano ${ }^{1,2}$ and R. L. Reis ${ }^{1,2}$ \\ Over the past several years, the definition of a scaffold for tissue engineering has changed \\ dramatically, from a material that acts only as an inert structural support for cell attachment to \\ serving as a more complex and dynamic environment for tissue development. This paper is a \\ review on the existing and on the new emerging techniques based on supercritical fluid \\ technology for the preparation of scaffolds and particles for tissue engineering applications. \\ Supercritical fluid technology has already proven to be feasible for many pharmaceutical \\ applications and is now emerging as an alternative to conventional materials' processing methods \\ for the preparation of three-dimensional structures and injectable particles suitable to be used in \\ regenerative medicine. The basic principles underlying each technique are here presented as \\ well as the advantages and disadvantages of each process. The state of the art is reviewed and \\ the major conclusions of the studies reported in the literature are discussed.
}

Keywords: Supercritical fluids, Scaffolds, Tissue engineering, Drug delivery, Polymer processing, Review

\section{Introduction}

Tissue engineering is a promising therapeutic approach that combines cells, biomaterials, and bioactive compounds. ${ }^{1,2}$ The emerging next generation of engineered tissues relies on the development of loaded scaffolds containing bioactive molecules in order to control the cellular function (e.g. growth or differentiation factors) or to act on the surrounding tissues (e.g. drugs such as anti-inflammatory agents or antibiotics). ${ }^{3,4}$ Hence, the strategy is to mimic matrix and provide necessary information or signaling for cell attachment, proliferation and differentiation to meet the requirement of dynamic reciprocity for tissue engineering.

The potential use of supercritical fluids (SCFs) for process improvements has led to an increasing interest in this technology over the past decade. The properties of these fluids, which can change between those of liquid and gas depending on the fluid density have been explored in a number of different techniques, such as extraction, impregnation, fractionation, adsorption, chromatography and crystallisation. Supercritical fluids can also serve as a reaction media in polymerisation or simply as a processing fluid in particle formation or foaming. Some techniques have already become commercial namely extraction, e.g. decaffeination, polymerisation and foaming. Particle formation is most likely to be the next major application. The use of SCFs in the

\footnotetext{
13B's Research Group - Biomaterials, Biodegradables and Biomimetics, University of Minho, Headquarters of the European Institute of Excellence on Tissue Engineering and Regenerative Medicine, AvePark, 4806909 Taipas, Guimarães, Portugal

${ }^{2}$ IBB - Institute for Biotechnology and Bioengineering, PT Government Associated Laboratory, Guimarães, Portugal

*Corresponding author, email aduarte@ dep.uminho.pt
}

biomedical area, namely in tissue engineering is one of the newest applications which has emerged in the paste few years and this review will focus on the work that has been developed in this field.

\section{Supercritical fluids: basic principles}

A substance exists in nature in either one of the three states of the matter: solid, liquid or gaseous. On a phase diagram of a pure substance these phases are defined by the phase boundaries. Nevertheless, beyond the so called critical point a dense phase occurs and the substance is said to be in a supercritical state. An SCF can be defined as a dense phase, which pressure and temperature are above its critical point (Fig. 1). At the critical point a single phase exists with properties common to the liquids, namely density, and common to the gases, such as viscosity, compressibility and mass diffusion coefficient. $^{5}$

The density values of the SCF enable the solvation power and the lower viscosities induce a higher diffusivity, thus facilitating mass transfer. ${ }^{6}$ Different SCFs are available but not all are suitable for the same applications. The choice of the SCF depends greatly in its physico-chemical properties (Table 1). ${ }^{7}$

Carbon dioxide is the most commonly used SCF as its critical parameters, specially its low critical temperature, make it very attractive for the processing of thermosensitive compounds, such as pharmaceuticals and other bioactive compounds. It presents other important advantages, since it is environmentally benign, nontoxic, non-flammable, non-corrosive, readily available and inexpensive. Furthermore, carbon dioxide has the status of a GRAS solvent, i.e. it is a generally regarded as safe solvent. Its elimination and the recovery of final products are easier in respect to conventional processes 


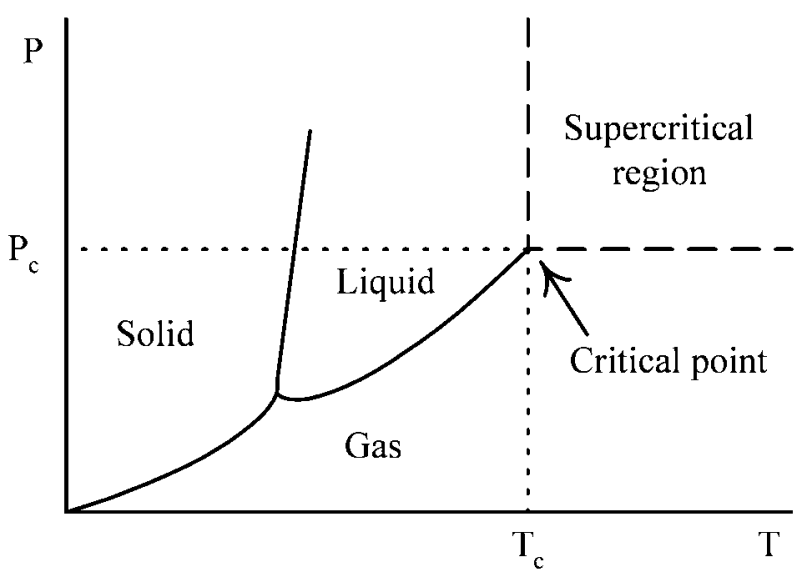

1 Phase diagram of pure substance

(no residue is left and a dry solid product is easily obtained, just by manipulating pressure), leading to processes with less energy consumption. Carbon dioxide can be recovered and reused, and therefore, does not contribute to the greenhouse effect.

As in products for medical and pharmaceutical applications, the presence of residual organic solvents is being rigorously controlled by international safety regulations, it is necessary to warrant the complete removal and absence of these substances, without exposing drugs to high temperatures, which may degrade them. ${ }^{8}$ Thus the use of SCF technology, namely using supercritical carbon dioxide appears as a very interesting alternative to the traditional processing methods.

\section{Particle formation}

Although three-dimensional (3D) porous structures have been recognised as the most appropriate to sustain cell adhesion, several applications in tissue engineering may take advantage of other designs. Injectable systems that can simultaneously act as scaffolds and delivery devices are becoming more and more attractive in this field, especially due to their non-invasive approach. ${ }^{9-11}$

Materials in particulate form for tissue engineering have been reviewed by Silva and co-authors in two papers where the basic concepts and the applications to bone regeneration are described. ${ }^{12,13}$ There is no doubt that tissue engineering strategies are moving towards systems that are able to combine materials, cells and growth factors. Materials in particulate form can play a role in this strategy as carriers for biologically active molecules. Furthermore, a better control in parameters such as porosity, pore size, surface area and mechanical

Table 1 Critical properties of the most common SFCs

\begin{tabular}{llc}
\hline & $\begin{array}{l}\text { Critical temperature } \\
\boldsymbol{T}_{\mathbf{c}}, \mathrm{K}\end{array}$ & $\begin{array}{c}\text { Critical pressure } \\
\boldsymbol{p}_{\mathrm{c}} \text {, bar }\end{array}$ \\
\hline Carbon dioxide & 304 & 74 \\
Water & 647 & 221 \\
Ethane & 305 & 49 \\
Ethane & 282 & 50 \\
Propane & 370 & 43 \\
Xenon & 290 & 58 \\
Ammonia & 406 & 114 \\
Nitrous oxide & 310 & 72 \\
Fluoroform & 299 & 49 \\
\hline
\end{tabular}

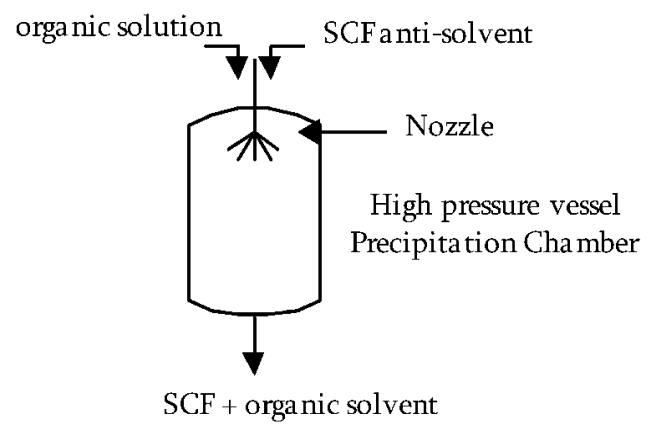

2 Schematic representation of SAS process: compound(s) are dissolved in organic solution; SCF acts as antisolvent promoting precipitation of solute

properties can be attained in the case of materials in particulate form.

In this sense, particle formation using SFC technology might see exciting perspectives. Supercritical fluid technology comprises several processes, leading to very different particles in terms of size, shape and morphology that offer various possibilities to address the different issues to be solved and to prepare various forms or formulations. The possibility of producing very small particles with a narrow size distribution using mild and inert conditions represents a major improvement over the conventional processes.

Different particle formation processes based on SFCs are available, including precipitation using the $\mathrm{SFC}$ as non-solvent and precipitation from supercritical solutions.

In the supercritical antisolvent (SAS) process, also referred in the literature as ASES, PCA or SEDS, the solute(s) are dissolved in an organic solvent, which is contacted with a supercritical solvent (Fig. 2). The principle of this process is to decrease the solvent power of the liquid by addition of an antisolvent in which the solute is insoluble.

The SAS technique presents several advantages, namely the fact that particles in the nanometre scale can be produced with easily controlled particle size and morphology. It is applicable to a wide range of materials and the processing can be conducted at near ambient temperatures. Therefore, this technique is good for processing small amounts of high added value products. On the other hand it presents some disadvantages, such as the use of organic solvents, even though it involves small volumes. For this reason, residual solvent might be present in the product and the separation of the gas and solvent may be required at industrial level, which makes the scale up of the process difficult.

This technique is largely applied in pharmaceuticals, namely for the preparation of dry inhalable powders, nanoparticle suspensions, microspheres or microcapsules of drug embedded in a carrier, among others. ${ }^{14}$ However, few studies using this technique have been reported in the literature for applications in tissue engineering. Vega-González and co-workers ${ }^{15,16}$ described the preparation of a fibrous network of polyL-lactic acid (PLLA), polymethylmethacrylate (PMMA) and a blend of poly- $\varepsilon$-caprolactone (PCL) with PMMA using the SAS precipitation process. Systems involving high molecular weight compounds may cause mass transfer limitations for the formation of discrete particles and fibres can be produced. As a result an 


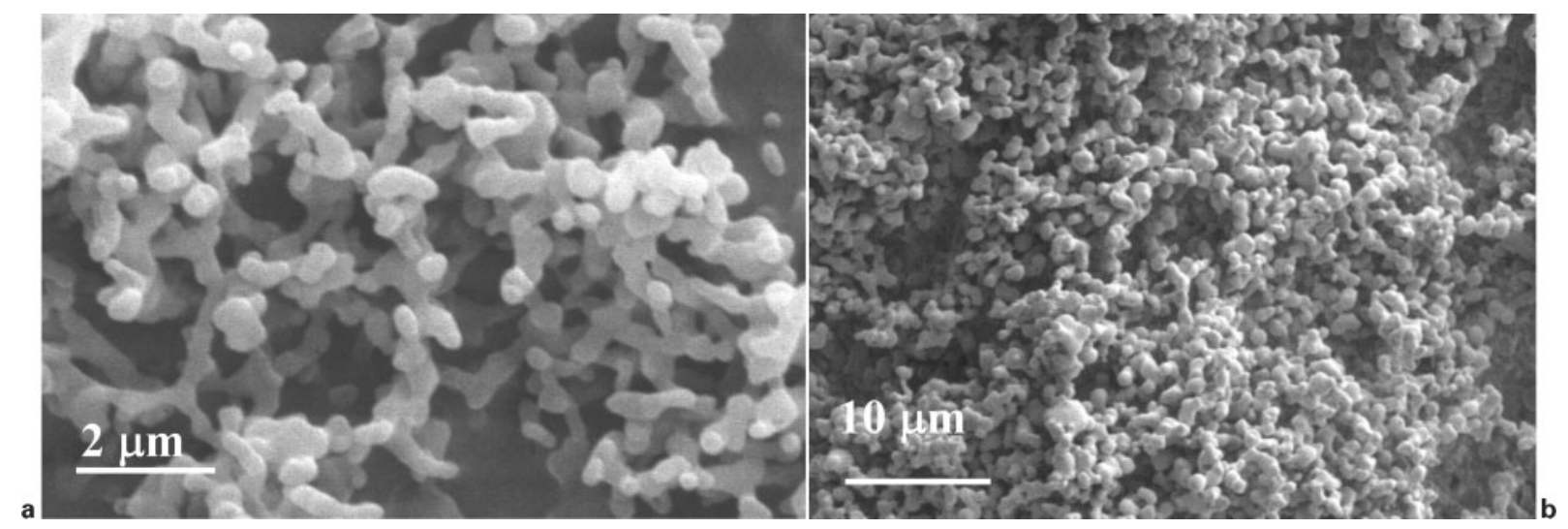

3 Image (SEM) of $a$ PLA/PEG and $b$ PHBV microparticles prepared by SAS

interconnected structure with potential applications in tissue engineering, which combines macro- and mesopores with a rough surface and high surface area is formed. The same authors have described a modification of the PCA (particles from a compressed antisolvent) to prepare composites of a polymer blend of PMMA/PCL with inorganic particles of titanium dioxide and poly(lactic acid) (PLA) with hydroxyapatite nanoparticles. A 3D network of nanofibres was constructed with potential applications as scaffolds in tissue engineering. ${ }^{17}$

Figure $3 a$ represents as an example polymeric blends of PLA and polyethylene glycol (PEG) processed by SAS. Natural origin polymers may also be processed using this technique. Costa and co-workers report the successful precipitation of particles from poly(3hydroxybutyrate-co-3-hydroxyvalerate) (PHBV). ${ }^{18}$ Figure $3 b$ shows PHBV particles precipitated from a dicloromethane solution.

Another technique widely used for particle formation is the so called PGSS, particles from gas saturated solutions. In this case, the compound(s) are melted in presence of a compressed gas and the liquid is pulverised towards a low pressure vessel (Fig. 4).

This process has a number of advantages, which make it very attractive for industrial purposes. It does not require the use of organic solvents, has a low pressure of operation and therefore a low SCF consumption. It has

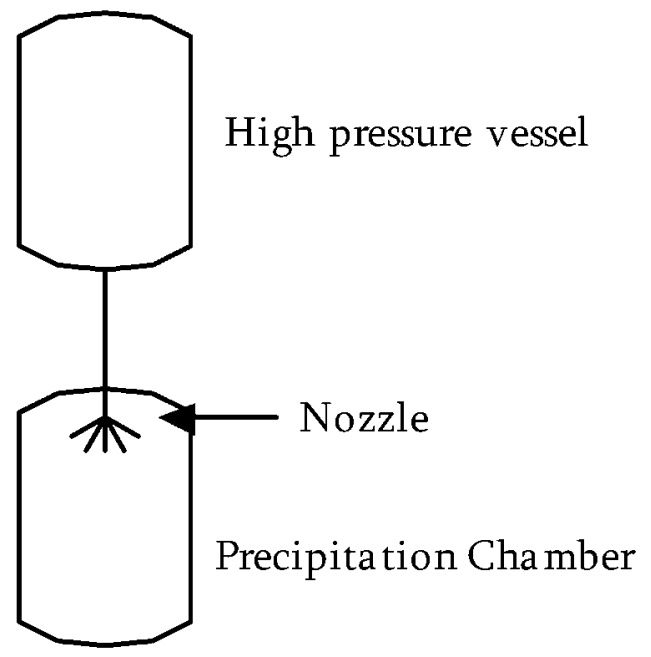

4 Schematic representation of PGSS process: SCF is dissolved in melted solution which is expanded into a low pressure vessel a high production capacity and can be easily scaled up. The major drawback of PGSS is the fact that it might have limited applications for pharmaceutical applications, depending on the operating temperature.

This technique has been studied particularly for the preparation of fibres and particles that may encapsulate bioactive molecules. The encapsulation of sensitive molecules, such as proteins has been successfully achieved using this process. Lysozyme, ribonuclease, insulin and calcitonin are examples of proteins processed with PGSS with minimal loss of their activity. ${ }^{19}$ This study proves that SCF mixing can be an alternative to the current processing options for protein loaded controlled release devices as it is solvent free, does not generate solvent/water interfaces and changes in the kinetics of carbon dioxide depressurisation, can lead to materials of variable density and surface roughness.

The choice on the supercritical technique to be used for particle formation depends on the characteristics of the material to be processed but also on the purpose and the morphology desired for the particles. It should be noted however that particle size depends greatly on the systems processed and, particularly, on the diameter of the nozzle used for processing. Some materials can be processed either by SAS or PGSS. In these cases the technological features (Table 2) of each of the processes should be taken into account. This is especially important when an industrial process is planned.

\section{Preparation of $3 D$ scaffolds}

One of the most important stages of tissue engineering is the design and processing of a porous 3D structure, with high porosity, high interconnectivity between the pores and uniform distribution made form a biodegradable polymer or composite. Several techniques are reported in the literature for the preparation of $3 \mathrm{D}$ scaffolds. ${ }^{20}$ Conventionally, 3D structures can be obtained by processes such as solvent casting - particle leaching, ${ }^{21}$ freeze drying - particle leaching, ${ }^{22}$ thermally induced phase separation, ${ }^{23}$ compression moulding, ${ }^{24}$ injection moulding, ${ }^{25,26}$ extrusion, ${ }^{27}$ foaming, ${ }^{28}$ wet spinning ${ }^{29}$ and electrospinning, ${ }^{30}$ among others. ${ }^{31}$ The advantages of these processes have, however, to be weight against the fact that these normally involve the use of large amounts of organic solvents, and further purification and drying steps are often needed. Additionally, some of these techniques are performed at high temperatures, which may degrade thermolabile components, such as 


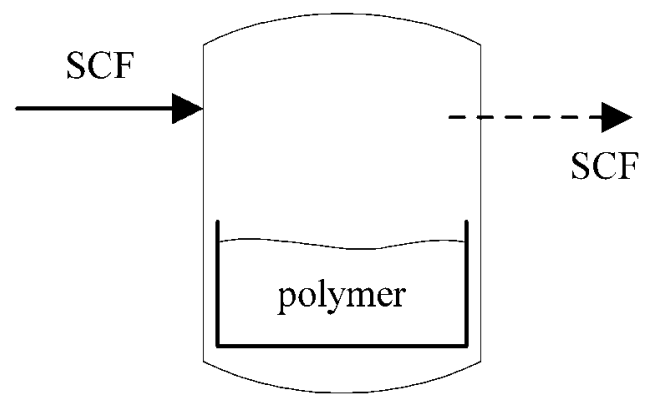

5 Schematic representation of SFC foaming process: polymer is saturated with $\mathrm{CO}_{2}$ under supercritical conditions followed by rapid depressurisation to atmospheric pressure

pharmaceutical drugs and bioactive agents. For these reasons there is the need to develop new technologies that are able to avoid or reduce the use of organic solvents and that operate at mild conditions are of great interest. Supercritical fluid technology appears to be an alternative to the conventional processes and several techniques are described in the literature for processing of biopolymers and biomedical devices. From the techniques available, the most commonly used for the preparation of 3D scaffolds for tissue engineering purposes include gas foaming and phase inversion processes.

\section{Gas foaming}

One of the most commonly used process for polymeric foaming is the so called thermally induced phase separation, where the blowing agent is usually an organic solvent like pentane. Other methods of preparing polymeric foams are available, such as foaming by means of a chemical foaming agent or by casting and leaching, where the porogen is usually a water soluble salt. The main drawbacks of the conventional methods are the possibility of leaving unwanted contaminations in the polymeric foams, such as residual solvents and salts, or the emission of harmful solvents. ${ }^{32}$

Gas foaming is a good alternative to these processes as no organic solvents or chemicals are used. Instead, nitrogen or carbon dioxide are used as blowing agents. When carbon dioxide is used one can take advantage of its plasticising properties. In this technique, the polymer is exposed to carbon dioxide, which plasticises the polymer by reducing the glass transition temperature. On venting the $\mathrm{CO}_{2}$ by depressurisation, thermodynamic instability causes supersaturation of the carbon dioxide dissolved in the polymer matrix and hence, nucleation of cells occurs (Fig. 5). ${ }^{33}$

The main requirement of the $\mathrm{CO}_{2}$ foaming process is that $\mathrm{CO}_{2}$ can be dissolved in a sufficient amount in the polymer. This excludes for instance, the use of polymers which have a very low affinity for $\mathrm{CO}_{2}$. Therefore, this technique may not be used in polymers with high crystallinity or high glass transition temperatures and is more commonly applied to amorphous polymers.

A patent by de Ponti et al. ${ }^{34}$ describes the foaming of PLGA using supercritical carbon dioxide $\left(\mathrm{scCO}_{2}\right)$. In general, it appears that milder process conditions are favourable for a high porosity. Mooney and co-workers first described the used of supercritical foaming for the preparation of macroporous scaffolds for tissue engineering applications. ${ }^{35,36}$ In their work, the possibility of producing matrices with porous surfaces and interconnected pore structrures of $\mathrm{P}_{\mathrm{D}, \mathrm{L}} \mathrm{LGA}$ was evaluated and very promising results were obtained.

In fact, much of the research that has been carried out in this field is based on homopolymers and copolymers of lactic and glycolic acids as they are attractive candidates for the fabrication of tissue engineering scaffolds. ${ }^{37}$ Furthermore, they present unique physical properties that allow them to be processable by this technique (Table 3). ${ }^{38}$

Tai and co-workers ${ }^{39}$ reported a very complete study on the effect of operating conditions in pore size and structure of tissue engineering scaffolds prepared with different blends of $\mathrm{P}_{\mathrm{D}, \mathrm{L}} \mathrm{LA}$ and PLGA. The authors concluded that indeed the pore size and the structure of the scaffolds could be tailored just by tuning the processing conditions. This conclusion is of utmost importance in order to develop scaffolds with the desired characteristics.

Different successful studies are described in the literature. Mathieu et $a l^{40}$ prepared bioresorbable ceramic polymer composites and demonstrated the flexibility of gas foaming to produce structures with a wide range of applications. Furthermore, biocompatibility studies demonstrated that PLA and PLA/HA (hydroxyapatite) scaffolds allow cell proliferation and differentiation. Georgiou et al. ${ }^{41}$ report another work performed with the aim of re-enforcing scaffolds for

Table 2 Technological features of SAS and PGSS processes

\begin{tabular}{lll}
\hline & SAS & PGSS \\
\hline Process & Semicontinuos & Continuous \\
Role SCF & Antisolvent & Solute \\
Gas demand & Medium & Low \\
Pressure & Low to medium & Low to medium \\
Organic solvent & Yes & Non \\
Volume of pressurised equipment & Medium to large & Small \\
Separation gas/solid & Easy & Easy \\
Separation gas/solvent & Difficult & Not applicable \\
\hline
\end{tabular}

Table 3 Physical properties of synthetic biodegradable polyesters used as scaffolds for tissue engineering

\begin{tabular}{lccr} 
& Poly(gycolic acid) & Poly(L-lactic acid) & Poly( $\varepsilon$-caprolactone) \\
\hline$T_{\mathrm{m}},{ }^{\circ} \mathrm{C}$ & 230 & 170 & 60 \\
$T_{\mathrm{g}},{ }^{\circ} \mathrm{C}$ & 36 & 56 & -60 \\
\hline
\end{tabular}


tissue engineering applications. In that work, composite scaffolds of PLA and phosphate glass were prepared.

Another study proposes the use of PLGA 50:50 and PLGA 85:15 (wt-\%) as scaffolds for liver tissue regeneration. The sponges were produced by $\mathrm{CO}_{2}$ gas foaming and the main goal was to create a substrate to grow human hepatoma cell line (Hep3B). ${ }^{42}$

Another polymer, which can be processed by gas foaming and that has potential application in the biomedical area is PCL. Microcellular foams of PCL have been prepared and are reported by Jenkins et $a .^{43}$ Leonard and co-workers ${ }^{44}$ also report a study on the characterisation of porous structures of biodegradable scaffolds using supercritical carbon dioxide as a foaming agent and in their study they conclude that the structure obtained is more homogeneous when the foaming process is performed at pressures higher than 250 bar.

Recently, supercritical gas foaming has been described to prepare porous and interconnected structures from chitin hydrogels. ${ }^{45}$ The work of Tsioptsias et al. reports for the first time the ability of carbon dioxide to foam hydrogels. It was found that the dissolution of carbon dioxide in the gel is the mechanism that governs the production of a porous matrix. The same methodology was applied for the preparation of micro- and nanoporous composite materials of cellulose. ${ }^{46}$ In this study, novel cellulose-composite porous materials were produced from hydrogels and alcogels. This technique can also be applied for the preparation of composite materials, such as cellulose hydroxyapatite constructs. ${ }^{47}$

Supercritical foaming has also been reported to prepare PCL scaffolds impregnated with active agents. ${ }^{48}$ Sudan Red G was selected in this study as a model agent and it was incorporated in a one step process in the bulk of the scaffold.

Aydin et al. have described the processing of polymeric blends. ${ }^{49}$ In their work, scaffolds of a copolymer (L-lactic acid and $\varepsilon$-caprolactone) have been successfully prepared by the supercritical assisted foaming process.

The foaming process can also be coupled with other processing techniques to improve the properties of the scaffolds prepared. Cellular composites of PLA reinforced with glass fibres were prepared in a two step process. ${ }^{50}$ A preform of the composite was prepared by extrusion and fibre bonding and in a subsequent step the scaffolds were foamed by supercritical gas foaming. Novel generation of light weight scaffolds with continuous fibres oriented in selective directions can be therefore prepared.

Another recent study, by Salerno and co-workers, ${ }^{51}$ presents the possibility of preparing a bimodal PCL scaffold combining the gas foaming technique and selective polymer extraction. Results showed that the combination of these two techniques allow the preparation of PCL scaffolds with a multiscaled and higly interconnected microstructure characterised by mechanical properties suitable for load bearing applications.

Velasco and coworkers ${ }^{52}$ suggested the preparation of porous polymeric scaffolds incorporating ibuprofen for tissue engineering of bone and cartilage. Blends of PMMA-PLA impregnated with the drug have shown very interesting behaviour in terms of drug release profile and good biocompatibility.
The gas foaming technique is also a very promising technique for the preparation of scaffolds loaded with growth factors and cells. Howdle and coworkers ${ }^{53}$ have shown the encapsulation of proteins in biocompatible and biodegradable polymers such as PLA, PLGA and PCL is feasible at relatively low temperatures and moderate pressures.

An attempt to prepare scaffolds with single and dual protein release from PLA scaffolds was successfully described by Ginty and co-workers. ${ }^{54}$ The results showed that it is possible to control the protein release profile and distinct release profiles can be obtained for each protein in the case of dual release. Furthermore, PLA was blended with PEG to increase the water uptake of the resultant scaffold and modify the release kinetics of the encapsulated protein.

The ability to generate porous structures in supercritical carbon dioxide, which are able to release angiogenic factors for tissue engineering applications, was demonstrated by Hile and co-workers who encapsulated basic fibroblastic growth factor in $P_{D . L} L G A$ foams. ${ }^{55}$ Another work performed by Yang et al. ${ }^{56}$ used the same methodology to load the scaffolds with bone morphogenetic protein 2 .

The capacity to deliver growth factors in combination with appropriate progenitor or stem cells to sites for tissue regeneration promoting angiogenesis and osteogenesis offers therapeutic opportunities in regenerative medicine. Vascular endothelial growth factor (VEGF165) was encapsulated in $\mathrm{P}_{\mathrm{D}, \mathrm{L}} \mathrm{LA}$, according to the technique described and human bone marrow stromal cells were seeded in the loaded matrixes. ${ }^{57}$ This study demonstrated the ability to deliver VEGF from scaffolds with seeded HBMSC to sites of bone defects with enhanced regeneration of a bone defect.

A non-viral gene delivery system suitable for tissue engineering applications was developed in a one step process using gas foaming and carbon dioxide as a foaming agent. ${ }^{58}$ DNA complexed with a polyamidoamine cationic polymer was incorporated in $P_{D, L} L A$. The results showed that the polyplexes can be released over a period of two months and a significant gene expression was achieved during this time.

One of the critical steps in tissue engineering is to achieve high cell seeding efficiencies. The common procedure is to deposit or inject cell suspensions into the scaffolds. The major drawback of this procedure is the fact that in many situations a large portion of the cells is washed out or fall down from the scaffold during the culturing period. A possible way to obtain a more homogeneous and stable construct would be to process the material and the cells together. However, cells do not survive to the processing conditions of most techniques. Supercritical technologies could provide adequate solutions to overcome these drawbacks. This would be one of the major advantages of using such technology in the field of tissue engineering and regenerative medicine.

A recent study reported by Ginty and co-workers ${ }^{59}$ has shown that mammalian cells can survive in a supercritical environment up to $5 \mathrm{~min}$. Myoblastic C2C12 cell line, 3T3 fibroblasts, chondrocytes and hepatocytes were tested. After this study, the same group developed a new injection system for the production of polymer/mammalian cell hybrid matrixes. ${ }^{60}$ The technology allows the reduction of the 


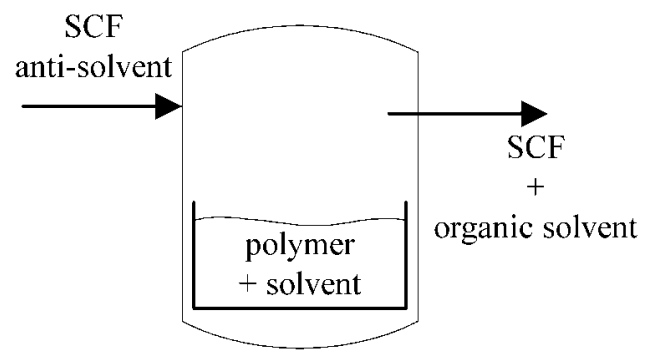

6 Schematic representation of supercritical assisted phase inversion process: polymer(s) are dissolved in organic solution; contact between solvent and SCF that acts as antisolvent promotes phase separation

contact time of the living cells in a supercritical environment, maximising their viability and functionally. Furthermore, this is a single step procedure and the cells are loaded in the scaffold during its preparation.

\section{Phase inversion}

The phase inversion method, also known as immersion precipitation technique, involves casting of a polymer solution onto an inert support followed by immersion of the support with the cast film into a bath filled with a non-solvent for the polymer. The contact between the solvent and the non-solvent causes the solution to be phase separated (Fig. 6). If the non-solvent used is a SCF this adds several advantages to the process. One of the most important advantages of the use of carbon dioxide is the fact that simply by tuning the process conditions, i.e. pressure and temperature one can tailor the final structure of the product. Additionally, when carbon dioxide is used as a non-solvent a subsequent drying step is avoided and the porous structure obtained is a dry product free of any residual solvent.

The use of carbon dioxide as a non-solvent for phase separation has been successfully reported in the literature for the preparation of different polymeric membranes. Regarding the preparation of porous scaffolds two polymers largely used for biomedical applications, PLLA, ${ }^{61}$ and PMMA ${ }^{62}$ were processed. Not only porous matrixes from these two materials were produced but also composite structures were developed. Tsivintzelis and co-workers ${ }^{63}$ report the preparation of nanocomposite scaffolds of PLLA with an organomodified mineral for the reinforcement of the polymeric matrix. Reverchon et al. ${ }^{64}$ prepared a drug loaded 3D structure of PMMA in order to evaluate the feasibility of using the phase inversion technique for the preparation of systems able to sustain the delivery of an active compound. These systems can be used either for tissue engineering or merely as drug delivery devices.

Recently our group has prepared porous structures of starch based polymers using this technique. It was for the first time reported the use of SCF assisted phase inversion in the processing on natural based polymers. ${ }^{65}$

The SPLA matrixes prepared by this method are characterised by a rough surface where micro- and macropores are visible. Such particular microstructure enhances the transport properties within the structure and could also encourage cell attachment and proliferation. The matrixes are also characterised by a highly interconnected porous structure. Figure 7 is a representative image of one of the scaffolds prepared at $150 \mathrm{bar}$ and $55^{\circ} \mathrm{C}$.

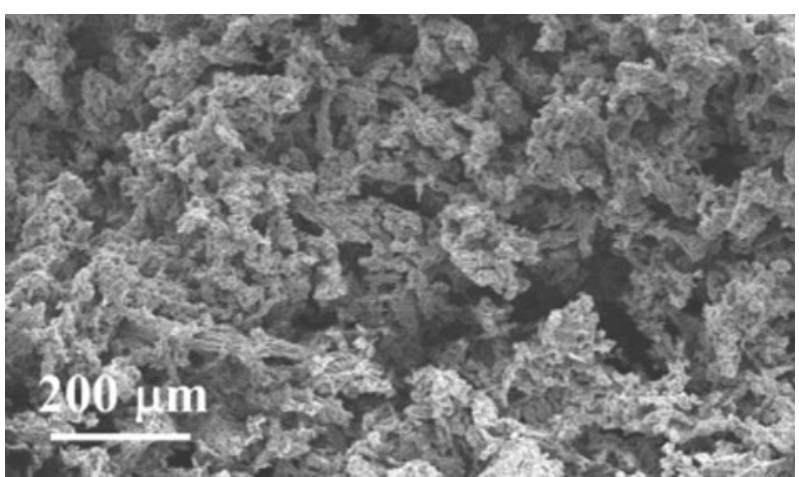

7 Image (SEM) of SPLA scaffold prepared by supercritical assisted phase inversion at 150 bar and $55^{\circ} \mathrm{C}$

The same methodology was used to evaluate the feasibility of preparing a drug loaded scaffold. Dexamethasone loaded SPLA scaffolds were prepared by supercritical assisted phase inversion and the release could be achieved up to 21 days. $^{66}$ Furthermore, the starch based scaffolds were loaded with bioactive glass. The in vitro bioactivity studies performed on the synthesised scaffolds have proven that the presence of bioactive glass can induce the formation of a bone-like apatite layer, which is very interesting for tissue engineering applications. ${ }^{67}$

Temtem and co-workers ${ }^{68}$ reported the precipitation of chitosan membranes from an aqueous solution of dilute acetic acid. Nonetheless, the presence of water and its poor solubility in the supercritical phase make the proposed process time consuming and energy intensive. The feasibility of processing chitosan from organic solutions was described by Duarte et al. ${ }^{69}$ Figure 8 represents a cross-section of a chitosan scaffold precipitated from a 1,1,1,3,3,3- hexa-fluoro-2-propanol (HFIP) solution. Although organic solvents are used, the use of $\mathrm{scCO}_{2}$ allow complete solvent removal as $\mathrm{CO}_{2}$ has good diffusivity and mass transfer properties. The ability of carbon dioxide to diffuse and penetrate in the bulk of the $3 \mathrm{D}$ matrix garantees the complete extraction of the organic solvent.

\section{Impregnation}

In tissue engineering, the development of a scaffold that can release at controlled rate a biomolecule, maintaining

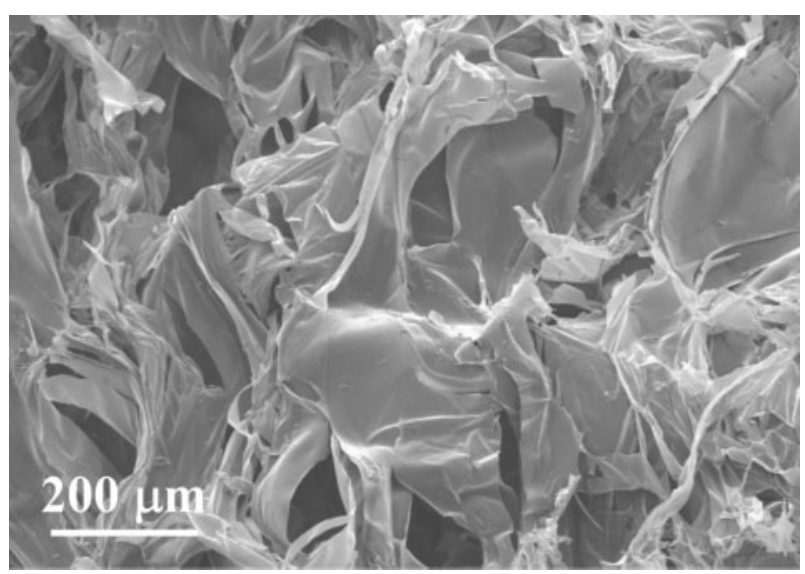

8 Image (SEM) of chitosan scaffold prepared by supercritical assisted phase inversion at 100 bar and $60^{\circ} \mathrm{C}$ 


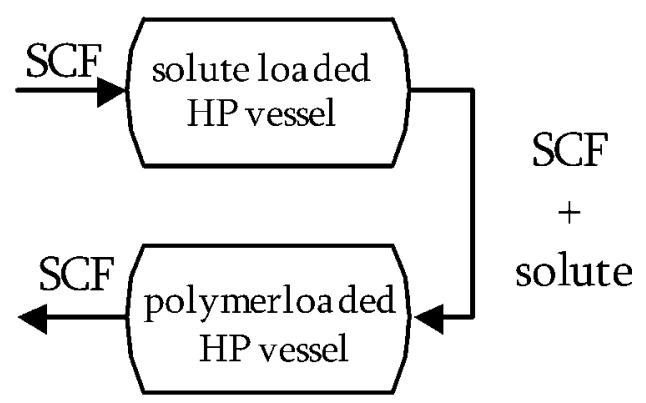

9 Schematic representation of SCF impregnation process: SCF saturated with drug component diffuses into polymeric matrix where drug component is absorbed and entrapped

at the same time its biological activity within days or weeks is of utmost importance. Small molecular weight drugs that control proliferation and differentiation of cells can be incorporated into biodegradable scaffolds to induce cellular differentiation and tissue remodelling. The scaffold plays, therefore an important role not only as a physical support but also as a bioactive element able to address adequate signals to the cells and tissues in the cell proliferation and differentiation.

The preparation of drug release products necessitates the use of a mobile phase that dissolves and transports the drug component, which also swells and stretches the polymer matrix, facilitating the diffusion of the drug and increasing the rate of impregnation. The interest on SCF impregnation process relies on the opportunity to use the high diffusivity, low surface tension and the ease of solvent recovery to prepare hybrid supports for tissue engineering, for long term delivery of therapeutic molecules, including unstable bioactive compounds, such as growth factors. Impregnation using SCF technology has proven to be feasible when the pharmaceutical compound is soluble in carbon dioxide and the polymer can be swollen by the SCF (Fig. 9). A high purity product, free of residual solvents is obtained, since no organic solvents are involved in the impregnation process. ${ }^{70,71}$ When depressurisation occurs, the gas rapidly diffuses out of the polymer, deplasticising it and warranting the complete removal of solvent, without exposing polymers and bioactive molecules to high temperatures, which may degrade them..$^{72,73}$

Supercritical fluid impregnation presents several advantages when compared to the conventional impregnation processes. It can be easily scaled up, the therapeutic molecule is homogeneously dispersed within the matrix due to the excellent diffusivity of carbon dioxide and the final product is recovered in the dry state. Nevertheless, this methodology is limited by the solubility of the drug in the SCF. Although carbon dioxide is the most commonly used SCF it does have limitations due to its lack of polarity and its associated deficiency of specific solvent solute interactions. To improve polarity/selectivity, it was found that the addition of small amounts of a so called cosolvent or entrainer (usually a polar substance) to an SCF can produce dramatic effects on its solvent power, some times up to several hundred percent solubility enhancement. ${ }^{74,75}$

This impregnation process has been mostly studied for the preparation of drug delivery systems, which are able to sustain the drug release within a certain period of time according to the final purpose of the delivery device. ${ }^{70}$ Only few studies using this technique have been reported with the purpose of developing delivery devices for tissue engineering.

Our group has proven the feasibility of preparing a loaded chitosan scaffold able to sustain the release of dexamethasone, ${ }^{76}$ a steroidal anti-inflammatory agent, which has been reported to induce effectively differentiation of bone marrow stem cells to osteoblasts, ${ }^{77}$ including the case when it is directly released inside the cells. $^{78}$

Molecules less stable, such as proteins can also be incorporated into matrixes using SFCs. The impregnation of molecules while minimising any chemical and structural change in the scaffold is an important advantage of this technique. Sproule and co-workers ${ }^{79}$ reported the successful impregnation of a protein in PMMA scaffolds for biomedical applications. Furthermore, results show that the processing conditions did not compromise the protein activity. Such kind of results suggests that it may be possible to load and delivery growth factors using this technique.

Gong et $a l^{80}$ used SCF assisted impregnation and foaming to prepare porous drug PEM/THFM (poly (ethylmethacrylate)/tetrahydrofurfurylmethacrylate) systems. This system has shown to have applications, for example, in cartilage reparation. Another group has tested the impregnation of polymers prepared by electrospinning, namely poly-caprolactone fibres. ${ }^{81} \mathrm{CO}_{2}$ impregnation of these scaffolds may provide a method for tailoring the chemistry of these relatively high surface area scaffolds without altering their biomimetic architecture. In their work, is reported the impregnation of a test compound, carboxytetramethylrhodamine and its release was monitored up to 30 days. The authors concluded that subcritical $\mathrm{CO}_{2}$ conditions could be used to embed chemical functionality into tissue engineering scaffolds without a loss of form.

Chemistry can also be performed impregnating monomers into porous matrixes after its preparation or during the scaffold processing. This results in scaffolds with different properties, that may be interesting for particular applications. For example, Temtem et al. ${ }^{82}$ have reported the impregnation of poly( $\mathrm{N}$-isopropylacrylamide), PNIPAAm in a chitosan scaffold. In this work, a chitosan scaffold was used as a matrix for the in situ polymerisation of NIPA in $\mathrm{scCO}_{2}$. This allows matrixes to be produced with thermoresponsive capability that could be used as systems for switchable release of molecules or smart scaffolds for tissue engineering applications. Partap and coworkers ${ }^{83}$ prepared porous natural synthetic polymer composites using the SFC assisted impregnation process. Their results suggest that alginate foams impregnated with hydroxyethyl methacrylate are potentially suitable materials in applications such as tissue engineering scaffolds, where mechanical conditioning is desired to stimulate cells for development of neo tissue growth.

\section{Other techniques}

Other techniques have been described in literature for the preparation of enhanced materials with potential applications in tissue engineering. This is a very recent research field and therefore some of these processes are not extensively studied. 
Zhang and co-workers ${ }^{84}$ reported a new technique for the preparation of aligned porous materials especially conceived to serve as scaffolds for aligned nerve growth. In this process, so called directional freezing of solutions in liquid $\mathrm{CO}_{2}$, the solute is dissolved in liquid carbon dioxide and the column is immersed in a liquid nitrogen bath until it is completely submerged. The gaseous $\mathrm{CO}_{2}$ is sublimed from the sample during slow warming, upon venting the column, the sample was recovered directly from the tube as a continuous monolith.

Another research group developed a $\mathrm{CO}_{2}$ assisted assembly method which offers a process suitable for the simultaneous assembly of a large number of micronanostructures containing cells and/or biomolecules. ${ }^{85}$ Yang and coworkers explore the ability of carbon dioxide to fuse polymeric microstrucutres in an aqueous environment. Furthermore, the integration of cells and/ or biomolecules in the fabrication process was evaluated. A complex 3D scaffold model impregnated with mESCs and 3T3 fibroblasts was successfully produced.

Recently, a new SCF assisted process was proposed to prepare scaffolds for tissue replacement. ${ }^{86}$ In this technique a polymeric aerogel is prepared with a solid porogen and in a subsequent step the gel is dried using supercritical carbon dioxide. The result is a dry porous material with potential applications for bone implants.

Surface modification of polymers by graft copolymerisation adds unique properties to polymer surfaces, which may have strong influence in the cell attachment and proliferation. Grafting of polymer surfaces using supercritical carbon dioxide has been tested for the preparation of polyvinylidene fluoride membranes. ${ }^{87}$ Supercritical $\mathrm{CO}_{2}$, acts as a solvent and carrier agent, and can accelerate mass transfer of monomers inside polymer matrixes and facilitate the graft copolymerisation on the surface of the membrane and within membrane pores.

The fabrication of microtextured surfaced using a supercritical assisted technology has been described in the work of Fujita and coworkers. ${ }^{88}$ In this work, a new embossing technique that does not need the use of a releasing agent or a chemical reaction that may alter the surface chemistry is described. It is further reported the feasibility to produce fine substrates of polycarbonate suitable for evaluating the effect of surface topography on cell attachment.

Other techniques that present potential for use in the preparation of 3D structures for tissue engineering purposes are SCF assisted injection moulding and extrusion. The extrusion process has so far only been reported for applications in drug delivery and in the preparation of controlled delivery devices. ${ }^{89-91}$ Nonetheless these techniques might see in the future a new range of applications, namely the preparation of porous scaffolds with or without bioactive compounds incorporated.

\section{Conclusions and perspectives}

Supercritical fluids appear to be an interesting alternative to the conventional processes for the processing of macromolecules and bioactive compounds in the context of biomedical applications, including tissue engineering. Several techniques have been reported in the literature and the field is continuously growing. As a reflection of that is the increasing number in papers published every year.

From the preparation of microparticles to the development of 3D structures, SCFs have evolved and present now a wide range of alternative methods that operate under mild operating conditions and take advantage of the tunable properties of the fluid phase. However, any advantage of these processes has always to be weighted against the cost and inconvenience of the higher pressures needed.

Different research areas such as polymers precipitation, from gas saturated solutions or using $\mathrm{CO}_{2}$ as an antisolvent, gas foaming, supercritical assisted phase inversion, incorporation of bioactive compounds and cells, surface modification, extrusion and sterilisation present the current trends of the use of SCF technology for tissue engineering purposes. The novelty of these technologies opens a wide range of opportunities for the preparation of enhanced materials that function not only as an inert structural support for cell attachment but act as a more complex and dynamic environment for tissue development.

\section{Acknowledgment}

Ana Rita C. Duarte is grateful for financial support from Fundação para a Ciência e Tecnologia through the grant no. SFRH/BPD/34994/2007.

\section{References}

1. X. Liu and P. X. Ma: Ann. Biomed. Eng., 2004, 32, (3), 477.

2. D. W. Hutmacher, J. T. Schantz, C. X. F. Lam, K. C. Tan and T. C. Lim: J. Tissue Eng. Regen. Med., 2007, 1, 245-260.

3. P. B. Malafaya, G. A. Silva, E. T. Baran and R. L. Reis: Curr. Opin. Solid State Mater. Sci., 2002, 6, (4), 283-295.

4. P. B. Malafaya, G. A. Silva, E. T. Baran and R. L. Reis: Curr. Opin. Solid State Mater. Sci., 2002, 6, (4), 297-312.

5. I. Pasquali, R. Betteni and F. Giordano: Eur. J. Pharm. Sci., 2006, 27, 299-310.

6. V. K. Kakumanu and A. K. Bansal: Business Briefing: Labtech, Sep. 2004, 70-72.

7. T. Clifford: 'Fundamentals of supercritical fluids'; 1998, Oxford, Oxford University Press.

8. 'Impurities residual solvents', CPMP/ICH/283/95, ICH guideline Q3C, 1997.

9. M. E. Gomes, R. L. Reis and A. G. Mikos: in 'Biodegradable systems in tissue engineering and regenerative medicine'; 2005, Boca Raton, FL, CRC Press.

10. J. D. Kretlow, L. Klouda and A. G. Mikos: Adv. Drug Deliv. Rev., 2007, 59, (4-5), 263-273.

11. D. G. Cruz, J. E. Irvico, M. E. Gomes, J. L. G. Ribelles, M. S. Sánchez, R. L. Reis and J. F. Mano: J. Tissue Eng. Reg. Med., 2008, 2, (6), 378-380.

12. G. A. Silva, P. Ducheyne and R. L. Reis: J. Tissue Eng. Reg. Med., 2007, 1, 4-24.

13. G. A. Silva, O. P. Coutinho, P. Ducheyne and R. L. Reis: J. Tissue Eng. Reg. Med., 2007, 1, 97-109.

14. M. Perrut and J.-Y. Clavier: Ind. Eng. Chem. Res., 2003, 42, 63756383.

15. A. Vega-González, P. Subra-Paternault, A. M. López-Periago, C. A. García-González and C. Domingo: Eur. Polym. J., 2008, 44, (4), 1081-1094.

16. A. M. Lopéz-Periago, A. Vega, P. Subra, A. Argemí, J. Saurina, C. A. García-González and C. Domingo: J. Mater. Sci., 2008, 43, (6), 1939-1947.

17. C. A. García-González, A. Vega-González, A. M. López-Periago, P. Subra-Paternault and C. Domingo: Acta Biomater., 2009, 5, 1094-1103.

18. M. S. Costa, A. R. C. Duarte, M. M. Cardoso and C. M. M. Duarte: Int. J. Pharm., 2007, 328, (1-2), 72-77.

19. M. J. Whitaker, J. Haob, O. R. Davies, G. Serhatkulu, S. StolnikTrenkic, S. M. Howdle and K. M. Shakesheff: J. Control. Release, 2005, 101, 85-92. 
20. L. Moroni, J. R. de Wijn and C. A. van Blitterswijk: J. Biomater Sci. Polym. Ed., 2008, 19, (5), 543-572.

21. Q. Fu, M. N. Rahaman, F. Dogan and B. S. Bal: Biomed. Mater., 2008, 3, (2), 025005.

22. N. Sultana and M. Wang: J. Mater. Sci. Mater. Med., 2008, 19, (7), $2555-2561$.

23. J. Nakamatsu, F. G. Torres, O. P. Troncoso, M. L. Yuan and A. R. Boccaccini: Biomacromolecules, 2006, 7, (12), 3345-3355.

24. S. Ghosh, J. C. Viana, R. L. Reis and J. F. Mano: J. Mater. Sci. Mater. Med, 2007, 18, (2), 185-193.

25. M. E. Gomes, A. S. Ribeiro, P. B. Malafaya, R. L. Reis and A. M. Cunha: Biomaterials, 2001, 22, (9), 883-889.

26. S. Ghosh, J. C. Viana, R. L. Reis and J. F. Mano: Acta Biomater., 2008, 4, (4), 887-896.

27. M. E. Gomes, H. S. Azevedo, A. R. Moreira, V. Ellä, M. Kellomäki and R. L. Reis: J. Tissue Eng. Reg. Med., 2008, 2, (5), 243-252.

28. E. Chevalier, D. Chulia, C. Pouget and M. Viana: J. Pharm. Sci., 2007, 97, (3), 1135-1154.

29. K. Tuzlakoglu, C. M. Alves, J. F. Mano and R. L. Reis: Macromol. Biosci., 2004, 4, 811-819.

30. D. Liang, B. S. Hsiao and B. Chu: Adv. Drug Deliv. Rev., 2007, 59, (14), 1392-1412.

31. D. W. Hutmacher: J. Biomater. Sci. Polym., 2001, 12, 107.

32. L. J. M. Jacobs, M. F. Kemmere and J. T. F. Keurentjes: Green Chem., 2008, 10, 731-738.

33. A. I. Cooper: Adv. Mater., 2003, 15, (13), 1049.

34. R. De Ponti, R. Torricelli, A. Martini and E. Lardini: WO patent no. 9109073

35. D. J. Mooney, D. F. Baldwin, N. P. Suh, J. P. Vacanti and R. Langer: Biomaterials, 1996, 17, 1417-1422.

36. L. D. Harris, B. S. Kim and D. J. Mooney: J. Biomed. Mater. Res., 1998, 42, (3), 396-402.

37. L. Singh, V. Kumar and B. D. Ratner: Biomaterials, 2004, 25, (13), 2611-2617.

38. M. Suzuki and Y. Ikada: in 'Biodegradable systems in tissue engineering and regenerative medicine', (ed. L. Rui et al.), 3-12 2005, Boca Raton, FL, CRC press.

39. H. Tai, M. Mather, D. Howard, W. Wang, L. J. White, J. A. Crowe, S. P. Morgan, A. Chandra, D. J. Williams, S. M. Howdle and K. M. Shakesheff: Eur. Cells Mater., 2007, 14, 64-77.

40. L. M. Mathieu, M.-O. Montjovent, P.-E. Bourban, D. P. Pioletti and J.-A. E. Manson: J. Biomed. Mater. Res. A, 2005, 75A, (1), 89-97.

41. G. Georgiou, L. Mathieu, D. P. Pioletti, P.-E. Bourban, J.-A. E. Månson, J. C. Knowles and S. N. Nazhat: J. Biomed. Mater. Res. $B, 2007, \mathbf{8 0 B}, 322-331$

42. X. H. Zhu, L. Y. Lee, J. S. H. Jackson, Y. W. Tong and C.-H Wang: Biotechnol. Bioeng., 2008, 100, (5), 998-1009.

43. M. J. Jenkins, K. L. Harrison, M. M. C. G Silva, M. J. Whitaker, K. M. Shakesheff and S. M. Howdle: Eur. Polym. J., 2006, 42, 3145-3151.

44. A. Leonard, C. Colberg, G. Kerckhofs, M. Wevers, R. Jerome, J. P Picard, A. Germain and S. Blacher: J. Porous Mater., 2008, 15, (4), 397-403.

45. C. Tsiopsias and C. Panayiotou: J Supercrit. Fluids, 2008, 48, (2), 302-308.

46. C. Tsioptsias, A. Stefopoulos, I. Kokkinomalis, L. Papadopoulou and C. Panayiotou: Green Chem., 2008, 10, 965-971.

47. C. Tsioptsias and C. Panayiotou: Carbohydr. Polym., 2008, 74, 99-105.

48. K. Luetzow, R. Klein, T. Weigel, R. Apostel, A. Weiss and A. Lendlein: J. Biomech., 2007, 40, (Supp. 1), S80-S88.

49. H. M. Aydin, M. Türk, A. Çalimli and E. Pişkin: Int. J. Art Organs, 2006, 29, (9), 873-880.

50. M. Bühler, P.-E. Bourban and J.-A. E. Manson: Composites A, 2008, 39A, 1779-1786.

51. A. Salerno, D. Guarnieri, M. Iannone, S. Zeppetelli, E. Di Maio, S. Iannace and P. A. Netti: Acta Biomater., 2009, 5, (4), 1082-1093.

52. D. Velasco, C. Elvira and J. San Roman: Tissue Eng. A, 2008, 14A, (5), 897-898

53. S. M. Howdle, M. S. Watson, M. J. Whitaker, V. K. Popov, M. C. Davies, F. S. Mandel, J. D. Wang and K. M. Shakesheff: Chem Commun., 2001, 1, 109-110.

54. P. J. Ginty, J. J. A. Barry, L. J. White, S. M. Howdle and K. M. Shakesheff: Eur. J. Pharm. Biopharm., 2007, 68, (1), 82-89.

55. D. D. Hile, M. L. Amirpour, A. Akgerman and M. V. Pishko: J. Control. Release, 2000, 66, 177-185.

56. X. B. B. Yang, M. J. Whitaker, W. Sebald, N. Clarke, S. M Howdle, K. M. Shakesheff and R. O. C. Oreffo: Tissue Eng., 2004, 10, (7/8), 1037-1045.
57. J. M. Kanczler, P. J. Ginty, J. J. A. Barry, N. M. P. Clarke, S. M Howdle, K. M. Shakesheff and R. O. C. Oreffo: Biomaterials, 2008, 29, 1892-1900.

58. M. Heyde, K. A. Partridge, S. M. Howdle, R. O. C. Oreffo, M. C. Garnett and K. M. Shakesheff: Biotechnol. Bioeng., 2007, 98, (3), 679-693

59. P. J. Ginty, D. Howard, F. R. A. J. Rose, M. J. Whitaker, J. J. A. Barry, P. Tighe, S. R. Mutch, G. Serhatkulu, R. O. C. Oreffo, S. M. Howdle and K. M. Shakesheff: PNAS, 2006, 103, (19), 7426-7431.

60. P. J. Ginty, D. Howard, C. E. Upton, J. J. A. Barry, F. R. A. J. Rose, K. M. Shakesheff and S. M. Howdle: J. Supercrit. Fluids, 2008, 43, 535-541.

61. I. Tsivintzelis, E. Pavlidou and C. Panayiotou: J. Supercrit. Fluids, 2007, 40, 317

62. E. Reverchon, S. E. Rappo and S. Cardea: Polym. Eng. Sci., 2006, 46, 188-197.

63. I. Tsivintzelis, S. I. Marras, I. Zuburtikudis and C. Panayiotou: Polymer, 2007, 48, 6311.

64. E. Reverchon, S. Cardea and E. S. Rappo: J. Memb. Sci., 2006, 273, 97-105.

65. A. R. C. Duarte, J. F. Mano and R. L. Reis: J. Supercrit. Fluids, 2009, 49, 279-285.

66. A. R. C. Duarte, J. F. Mano and R. L. Reis: Acta Biomater., 2009, doi: 10.1016/j.actbio.2009.01.047.

67. A. R. C. Duarte, J. F. Mano and R. L. Reis: 2009, doi: 10.1016/ j.msec.2009.04.012

68. M. Temtem, L. M. C. Silva, P. Z. Andrade, F. dos Santos, C. L. da Silva, J. M. S. Cabral, M. M. Abecasis and A. Aguiar-Ricardo: J. Supercrit. Fluids, 2009, 48, (3), 269-277.

69. A. R. C. Duarte, J. F. Mano and R. L. Reis: 2009, Proc. 9th Int Symp. on 'Supercritical fluids' (ISSF 2009), Bordeaux, France, May 2009, 95 .

70. I. Kikic and F. Vecchione: Curr. Opin. Solid State Mater. Sci., 2003, 7, 399-405.

71. C. Elvira, A. Fanovich, M. Fernández, J. Fraile, J. S. Román and C. Domingo: J. Control. Release, 2004, 99, 231-240.

72. A. R. Berens, G. S. Huvard, R. W. Korsmeyer and F. W. Kunig: J. Appl. Polym. Sci., 1992, 46, 231-242.

73. S. G. Kazarian: 'Supercritical fluid impregnation of polymers for drug delivery', in 'Supercritical fluid technology for drug product development', 343; 2004, New York, Marcel Dekker, Inc.

74. G. Brunner: Fluid Phase Equilib., 1983, 10, 289-298.

75. C. A. Eckert, B. L. Knutson and P. G. Debenedetti: Nature, 1996, 383, 313-318.

76. A. R. C. Duarte, J. F. Mano and R. L. Reis: Eur. Polym. J., 2009, 45, 141-148.

77. J. J. Yoon, J. H. Kim and T. G. Park: Biomaterials, 2003, 24, 2323 2329.

78. J. M. Oliveira, N. Kotobuki, A. P. Marques, R. P. Pirraco, J. Benesch, M. Hirose, S. A. Costa, J. F. Mano, H. Ohgushi and R. L. Reis: Adv. Funct. Mater., 2008, 18, 1840-1853.

79. T. L. Sproule, J. A. Lee, H. Li, J. J. Lannutti and D. L. Tomasko: J. Supercrit. Fluids, 2004, 28, 241-248.

80. K. Gong, M. Braden, M. P. Patel, I. U. Rehman, Z. Zhang and J. A. Darr: J. Pharm. Sci., 2007, 96, (8), 2048-2056.

81. O. Ayodeji, E. Graham, D. Kniss, J. Lannutti and D. Tomasko: J. Supercrit. Fluids, 2007, 41, (1), 173-178.

82. M. Temtem, T. Casimiro, J. F. Mano and A. Aguiar-Ricardo: Green Chem., 2007, 9, (1), 75-79.

83. S. Partap, A. K. Hebb, I. U. Rehman and J. A. Darr: Polym. Bull., 2007, 58, (2), 849-860.

84. H. Zhang, J. Long and A. I. Cooper: J. Am. Chem. Soc., 2005, 127, 13482-13483.

85. Y. Yang, Y. Xie, X. Kang, L. J. Lee and D. A. Kniss: J. Am. Chem Soc., 2006, 128, 14040-14041.

86. E. Reverchon, S. Cardea and C. Rapuano: J. Supercrit. Fluids, 2008, 45, (3), 365-373.

87. G.-M. Qiu, L.-P. Zhua, B.-K. Zhua, Y.-Y. Xu and Q. L. Qiu: J. Supercrit. Fluids, 2008, 45, 374-383.

88. S. Fujita, D. Ono, M. Oshima and H. Iwata, Biomaterials, 2008, 29, $4494-4500$

89. G. Verreck, A. Decorte, H. Li, D. Tomasko, A. Arien, J. Peeters, P. Rombaut, G. van den Mooter and M. E. Brewster: J. Supercrit. Fluids, 2006, 28, 383-391.

90. J. G. Lyons, M. Hallinan, J. E. Kennedy, D. M. Devine, L. M. Geever, P. Blackie and C. L. Higginbotham: Int. J. Pharm., 2007, 329, 62-71.

91. G. Verreck, A. Decorte, K. Heymans, J. Adriaensen, D. Liu, D. Tomasko, A. Arien, J. Peeters, G. van den Mooter and M. E. Brewster: Int. J. Pharm., 2006, 327, 45-50. 